\title{
Moderating Effects Of Government Environmental Policies On Green Products Toward Consumer Buying Behavior
}

\author{
Muhammad Usman Saleem \\ School of Public Affairs \\ University of Science and Technology of China, \\ No. 96 JinZhai Road, Hefei, Anhui province, China \\ Ren Chong \\ School of Public Affairs \\ University of Science and Technology of China, \\ No. 96 JinZhai Road, Hefei, Anhui province, China \\ Anam Fatima \\ School of Public Affairs \\ University of Science and Technology of China, \\ No. 96 JinZhai Road, Hefei, Anhui province, China \\ Farhan Khan \\ School of Public Affairs \\ University of Science and Technology of China, \\ No. 96 JinZhai Road, Hefei, Anhui province, China
}

\begin{abstract}
Green marketing is the concept itself embodies the notion that the product of a given company is produced using environmentally friendly process. The down side is that the consumer need to be made aware regarding these initiatives by various companies and therefore labeling is of utmost importance. However, the question does arise whether the labeling is indeed because the company follows procedure or their packaging so that consumer can buy and they also satisfy the regulatory requirement as well. This study on consumer buying behavior is unique in nature, as no other study has been conducted before that is similar in nature. Hefei is a significant and upcoming tier-one city and central people government has started taking initiatives to uplift the city in a central economic zone. The study used policy as a moderator and there seems to be a unique effect of policy as the Chinese consumers is unlike any other as Chinese consumers are always well aware about their surroundings and very cautious about their consumables, therefore this is an ideal market where to check the component of policy. the result shows that the consumer in Hefei are having a high moral ethics and that helps develop their attitude towards becoming environmentally aware consumer. The moderation effect is also evident with the significance value .001 and shows that's the more a consumer is aware about the policy and labeling the more they want to become environmentally responsible consumer. The consumer is showing a stronger awareness and the overall conclusion desired from this study leads the conclusion that the consumer of Hefei is different from the others and exhibits an environmentally friendly attitude.
\end{abstract}

Keywords: governmental policy, green products, buying behavior, satisfaction, intention, China 


\section{INTRODUCTION}

The current marketing model is based on the use of the earth human resources and system in a way that is not sustainable (Peattie, 1999). The traditional point of view on the social responsibility of enterprises, which asserts that the manager of the company's and Directors are only responsible for the "owners" of the company to maximize profits. In the beginning of the years 1990, it is suggested that to include the responsibility to those who have a direct interest in the society (Klonoski, 1991). Instead of a corporation they ought to take account of the cause of its actions on the whole of the stakeholders (such as government and companies), as well as the environment and flora and fauna (ibid.).

The launch of communication campaigns based on the environment advertising is based on worry of being accused of "green washing" (ibid.). It is when a company is hiding the real effect of its goods as results on the atmosphere as the corporation are extraordinarily worried by the environmental issues (Green washing, 2009). Even if this revolution has not taken place as planned, the interest of the theme has not turned off. Grant (2008) contends that the green marketing is at a critical point and that what's we will have to decide if the subject continues to develop and accelerate. If a change in the paradigm of the conventional production to the ecological advertising occurs than companies will require to integrate sustainability keen on their strategies or else are likely to be left for the account (Grant, 2008). It will be situated for the organization and marketing specialists to be very well aware of on the issue and possess a detailed understanding of green advertising and how it will be able to form value.

Since the middle of the 1990s, ecological legislations have amplified, lead to an advanced level of attentiveness of ecological problems the big business world and loads of companies to be obliged to take account of these issue during their tactical planning in order to meet up more stringent environmental values (Banerjee, 1999). Independently of the legislation in addition to principles of numerous people, ask in broad to assume more dependability for their proceedings and the penalty thereof.

Concept of green advertising in public sector is immature enough and accordingly it has not been much studied or even do research (Grant, 2008; Hartmann \& Ibáñez, 2006; Baker \& Sinkula, 2005). Although numerous companies keep in check-implemented form of green inventiveness, very little have in reality put in place a green strategy at the enterprise level. It encourages State government which although may vary depending on the industry and perhaps in individual enterprise, the rapid acceptance of a formal process and well expressed green tactic may allow the companies the possibility of a viable benefit. Recital Olson's declares few wonder that how companies, which have without a doubt integrated a certain variety of green idea in the enterprise have done and for what circumstances. Accordingly, the intention of this study is to acquire an in-depth understanding of the object of environmental advertising, marketing strategic investigative how environmental advertising tactic can be developed and what incentive the enterprises have to do in order to meet government environmental guidelines or policies.

One of the goals of a marketing tactic is to optimize the advertising mix in contrast to the expectations and the requirements of the targeted marketplace (Fuller, 1999). The data of the company-targeted customers can give a priceless contribution to the decision-making process (ibid. p. 320). Fuller (1999) adds that the undifferentiated advertising to mass audience will often be unsuccessful to guarantee the satisfaction of the client and the return, and that segmentation of the market constitutes a more accurate to the understanding. 


\section{Motivation of this study}

To create a successful brand in the consumer product industry, companies usually have to include an environmental dimension. More than half of 18,000 surveyed consumers from all over the world said they were worried about environmental problems (GlobeScan, 2014). The green movement has so much momentum that the term "going green" had 15.6 million hits on Google in January 2008 (Erdman, 2008) and 31 million hits just over two months later. Marketing practitioners and academics attempt to identify and understand green consumers and their needs, and to develop market offerings that meet these needs (D'Souza et al., 2007). The main objective of this research article is to identify the different currents of thought, which could assist and guide consumers for researchers. So, our motivation to conduct this research to explore the effects of government environmental policies on environmentally responsible consumer buying behavior. So, we established our research problem: How the environmental green products purchase intention effects the environmentally responsible consumer buying behavior under the moderating effect of government green product policy for the environment?

\section{LITERATURE REVIEW}

The green advertising has been a major subject of academic research since its arrival on (Coddington, 1993; Fuller, 1999; Ottman, 1994). The attention has been called on the object at the end of 1970's when the American Marketing Association has organized the first workshop on the Ecological marketing in 1975, which resulted in the first book on the subject entitled Ecological marketing by Henion and Kinnear in 1976. The first definition of "green marketing" was according Henion and Kinnear (1976); the implementation of the marketing programs aimed the market segment respectful manners" (Banerjee, 1999). The procedure of planning, implementation and control of the growth, pricing, advertising and circulation of goods in a style that meets the subsequent three criteria: (1) The desires of the client are meet, (2) The goals be achieved, and (3) The procedure is well matched with the ecosystem.

Another group of studies have explored the fields of the assessment of the claims relating to the environment in green the advertisements. For example, Davis (1993) has stressed the need to present the objective, concrete, and the factual claims to describe ecological characteristics and in the favor of a company/product, since this critically affected the opinions of buyers.

Another study by Kangun, Carlson, \& Grove (1991), has shown that more than half of the green advertising reviewed contained at least an allegation confusing or deceptive that has been recognized to the absence of sufficient standards in the advertising of the environment and of the intense competition prevailing on the market. In the same vein, Carlson et al. (1993) analysis of the content of 100 ads green has revealed that in most cases of environmental claims were misleading/misleading, rather than to accept in the nature.

Aligned with the definitions above, Kotler \& Lee (2008) has defined the ecological purchase as "the purchase of efforts of supply which give preference to the products or services that are less harmful to the environment and health". In addition, Nik Abdul Rashid (2009) has conceptualized the intent to purchase green as the probability and the willingness of the person to give preference to environmentally friendly products compared with conventional products in their considerations of purchase. While Chan (2001), defined as the green purchasing a specific kind of a respectful behavior of consumers that are express their concern for the environment. 
Long-term orientation is one of the dimensions of the cultural orientation, which deals with the time - past, present and future. Long-term orientation is an aspect of the national culture and the values of the influence even the decision-making process (Bearden, 2006). Hofstede (2001) has mentioned "LTO as a trend toward the future, for the promotion of virtues oriented and reward in a particular of the perseverance and the economy". In other courses, it refers to the values, the society long term oriented values and the short term oriented values and the tradition.

McCormick, John (2001), defined the environmental policy as a promise to the laws, regulations, and other instrument of policy regarding environmental matters and sustainability. He has also represented that this policy may be intentionally taken to straight and supervise the human actions and thus avoid the injurious effects on the environment that surrounds us, with the biophysical environment and the natural assets that ensure that the transformation in the environment do not have injurious effects on human being.

Oxford Dictionary (1995) environmental policy puts the focus on the issues arising from the human influence on the environment having a negative influence on the human values such as health or the environment clean and green. The questions of the environment usually mentioned by the environmental policy is broad area including but beyond the boundaries to the air and water pollution, waste management, ecosystem management, the protection of the biodiversity, the protection of natural assets, wildlife and endangered species, and the protection of these natural resources for upcoming generations. Rushefsky, Mark E. (2002) has pleaded for the participation of the State in the form of forces ahead of the control of a person who's the issue of "parasitism" and the "tragedy of the common". It has defined the issue of parasitism is when the private marginal charge to take measures to shield the environment is larger than the marginal advantage, but the marginal social expense is smaller than the marginal social benefit. The pollution of the water in the river by the plant could be an excellent example of the issue of parasitism where the company must clean the water before drinking that the costs as a whole and it is the external expense to the factory that are responsible for this pollution.

The disaster of the common property is not destined to say when an individual is the owner of the commons; each person has an incentive to use the ordinary resources as much as he can. Mr. Mark argued that without the participation of the State, the commons is used as for instance of the tragedies of the policy are overfishing and overgrazing (Rushefsk, Mark, 2002).

The behavior of consumers has always been of great interest for the specialists of the marketing. The knowledge of the behavior of consumers contributes to the marketing to understand how consumers think, feel and select from other options such as the products, brands and other way of in which consumers are influenced by their environment, reference groups, family, and sellers and so on. In the context of the marketing, the term "consumer " refers not only to the act of purchase itself, but also to modes of global purchase: pre-sales and post-sales activities. The activity Pre-purchase may consist in the awareness of a need or want, and a search for evaluation and information on the products and brands that could satisfy it. Post-purchase: the evaluation of the purchased item in the use and the reduction of the anxiety, which accompanies the purchase of expensive and rarely purchased items. Each of these has implications for the purchase and implementation and pension that they lend themselves to different degrees of influence marketing (Foxall, 1987). Engel, et al. (1986) defines the behavior of the consumer as "acts of individuals directly involved in obtaining, the use and disposal of goods and economic services, including the decision-making process which precede and determine these acts". The simple observation provides a limited 
overview in the complex nature of the choice of consumers, and researchers have increasingly sought the concepts and more sophisticated methods of investigation provided by the behavioral sciences to understand, predict, and perhaps check the behavior of consumers in a more effective way.

This article presents a review of the literature, in the area of purchasing behavior of consumers. The first section, describes, the importance of various factors, including the mode of life and its impact on the purchasing behavior of consumers. The second section describes the prospects of dominant consumers positivistic. The third section presents an overview methodological and analytical of the traditional perspectives. The rest of this section is devoted to the presentation of the salient points of the debate between the non-recent positivist perspectives traditional and positivist approaches. These discussions around the questions are fundamentals assumptions and techniques of analysis of various other modes of inquiry.

\section{HYPOTHESIS}

H1: The relationship of green product purchase intention on the environmentally responsible consumer behavior.

H2: Assessing the moderating effect of government policy on environmentally responsible consumer buying behavior.

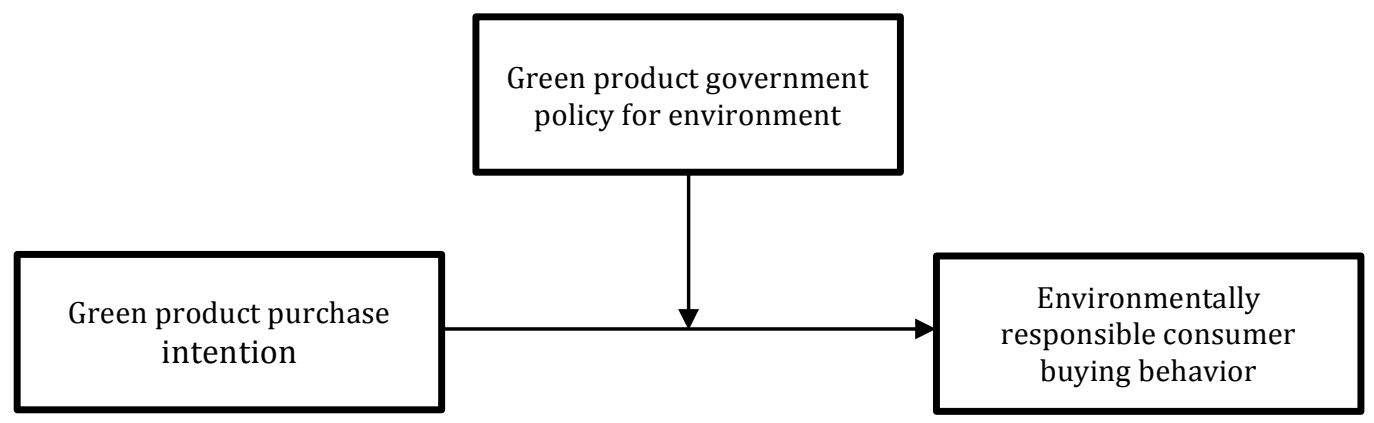

Figure 1: Research model

\section{Research methodology}

The preceding section discusses the theory and model used when conducting this research. This section present the practical approach and research method used in this article along with choice motivation and discussions on the methods problem. The literature used in this article was found through the University library. The most importantly used databases were Emerald, Elsevier (Science Direct) and Google scholar. The search words that were initially used were: "green marketing", "strategy", "competitive advantage", "environmental marketing", and "strategic marketing", "government environmental policy", "China”. A quantitative research is a suitable strategy when focusing on one or a small number of research units with the reason of achieving a deeper approaching into proceedings, relations and processes (Denscombe, 2000). Furthermore, Yin states that when answering different sets of questions, the researcher have to cover all the aspects of events, and when the focus is on a current phenomenon in a real-life context, quantitative research is the preferred approach (referred by Ghauri \& Grønhaug, 2005). As the aim of this research is to gain a deeper understanding: how green product purchase intention effects the environmentally responsible consumer buying behavior under the shed of government environmental policies?

Keeping in view the subject of this research, data was collected from persons whose age is more than 18 years and have some knowledge about green environmental by using the 
convenience sampling technique. The sample frame for this study comprised of 300 hundred respondents from Hefei, Anhui, China. Eighteen respondents did not complete their question papers. Therefore, these uncompleted question papers were dropped.

For analysis of our collected data, we use statistical software that is SPSS v20. This study used Cronbach's alpha to evaluate the internal consistency of the construct measured. For checking the correlation between two variables i.e. "Green product purchase intention" and "Environmentally responsible consumer buying behavior" and then we apply correlation and regression for checking the significance between variables and moderator.

\section{FINDINGS}

H1: The relationship of green product purchase intention on the environmentally responsible consumer behaviour

A linear regression was calculated to predict Environmentally responsible consumer behavior based on Green product purchase intentions and a significant regression equation was found $(\mathrm{F}(1,279)=53.27, p<.000)$, with an $R^{2}$ of .157 . China is often haunted by severe crises related to the degradation of the Environment (Rozelle et al., 1997), for example, the water and air pollution, solid waste, overflow of desertification, and the reduction of biodiversity This exacerbation conditions of the environment in China raises a critical question about the relationship between the consumption, the advertising and the natural environment, Research in social psychology suggests that the intentions are the best predictor of a behavior of the individual because they allow each individual to integrate in an independent manner all the factors that can influence the real behavior.

MODEL SUMMARY

\begin{tabular}{|l|r|r|r|r|}
\hline & & & & \\
Model & $\mathrm{R}$ & R Square & Adjusted R Square & $\begin{array}{c}\text { Std. Error of the } \\
\text { Estimate }\end{array}$ \\
\hline 1 & $.400^{\mathrm{a}}$ & .160 & .157 & .361 \\
\hline
\end{tabular}

a. Predictors: (Constant), IntentionaA

\begin{tabular}{|rr|r|r|r|r|r|}
\hline \multicolumn{1}{|l|}{} & & & & \\
Model & & Sum of Squares & Df & Mean Square & F & Sig. \\
\hline 1 & Regression & 6.964 & 1 & 6.964 & 53.276 & $.000^{\mathrm{b}}$ \\
& & 36.469 & 279 & .131 & & \\
& Residual & 43.433 & 280 & & \\
& Total & & & \\
\hline
\end{tabular}

a. Dependent Variable: EVBAA

b. Predictors: (Constant), IntentionaA 


\begin{tabular}{|c|c|c|c|c|c|c|}
\hline \multicolumn{7}{|c|}{ COEFFICIENTS $^{A}$} \\
\hline \multirow{2}{*}{\multicolumn{2}{|c|}{ Model }} & \multicolumn{2}{|c|}{ Unstandardized Coefficients } & \multirow{2}{*}{$\begin{array}{c}\text { Standardized } \\
\text { Coefficients }\end{array}$} & \multirow[b]{2}{*}{$\mathrm{t}$} & \multirow[b]{2}{*}{ Sig. } \\
\hline & & $\mathrm{B}$ & Std. Error & & & \\
\hline \multirow[t]{2}{*}{1} & (Constant) & 2.262 & .177 & & 12.778 & .000 \\
\hline & IntentionaA & .335 & .046 & .400 & 7.299 & .000 \\
\hline
\end{tabular}

a. Dependent Variable: EVBAA

H2: Assessing the moderating effect of government policy on environmentally responsible consumer buying behavior

As shown in Table below, this part focused on investigating the moderating effect of policy on the relationship between consumer buying behavior and environmentally responsible consumer behavior. The following tables describe the standard regression analysis regarding moderating effect of environment policy between green purchase intention and environmentally responsible consumer buying behavior from empirical result it is driven that ( $\beta$ intentioanA*Policy $=-.247, \mathrm{p}<.001$ ) that means that policy is positively lies between both of them ,

Environmental policy puts the focus on the problems arising from the human impact on the environment having a negative impact on the human values such as health or the environment clean and green". The questions of the environment generally addressed by the environmental policy is vast area including but not limited to the air and water pollution, waste management, ecosystem management, the protection of the biodiversity, the protection of natural resources, wildlife and endangered species, and the preservation of these natural resources for future generations

MODEL SUMMARY

\begin{tabular}{|l|r|r|r|r|}
\hline 1 & $.486^{\mathrm{a}}$ & .236 & .228 & .346 \\
\hline
\end{tabular}

a. Predictors: (Constant), policyA, IntentionaA, mod

ANOVA ${ }^{\mathrm{A}}$

\begin{tabular}{|c|c|c|c|c|c|c|}
\hline \multicolumn{2}{|r|}{ Model } & Sum of Squares & $\mathrm{df}$ & Mean Square & $\mathrm{F}$ & Sig. \\
\hline 1 & Regression & 10.253 & 3 & 3.418 & 28.532 & $.000^{\mathrm{b}}$ \\
\hline & Residual & 33.180 & 277 & .120 & & \\
\hline & Total & 43.433 & 280 & & & \\
\hline
\end{tabular}

a. Dependent Variable: EVBAA

b. Predictors: (Constant), policyA, IntentionaA, mod 


\begin{tabular}{|c|c|c|c|c|c|c|}
\hline \multicolumn{7}{|c|}{ COEFFICIENTS $^{A}$} \\
\hline \multirow{2}{*}{\multicolumn{2}{|c|}{ Model }} & \multicolumn{2}{|c|}{ Unstandardized Coefficients } & \multirow{2}{*}{$\begin{array}{c}\begin{array}{c}\text { Standardized } \\
\text { Coefficients }\end{array} \\
\text { Beta }\end{array}$} & \multirow[b]{2}{*}{$\mathrm{t}$} & \multirow[b]{2}{*}{ Sig. } \\
\hline & & $\mathrm{B}$ & Std. Error & & & \\
\hline \multirow[t]{4}{*}{1} & (Constant) & -.354 & .723 & & -.490 & .624 \\
\hline & IntentionaA & .923 & .195 & 1.102 & 4.742 & .000 \\
\hline & $\bmod$ & -.247 & .072 & -1.836 & -3.437 & .001 \\
\hline & policyA & 1.074 & .273 & 1.636 & 3.936 & .000 \\
\hline
\end{tabular}

a. Dependent Variable: EVBAA

\section{DISCUSSION AND CONCLUSION}

This study concerns about the environment that come into the forefront of thinking in People's Republic of China about global climate change and thus again, it is important to reconsider the consumer attitudes towards environmentally responsible behavior and also products and promotion tools towards buying behavior. The results of this study show that most consumers are environmentally responsible with more positive attitudes toward government policies and intentions. This study also found that consumers are willing to pay more for these types of products. The revised standard and purified study needs to examine these issues in the future and should be useful for both academics and practitioners in the study of green consumer responses to marketing efforts and the resulting consumer behavior.

Although there is some controversy in environmental policy framework regarding the need, fairness and cost effectiveness, that is accepted as a critical issue worldwide. Researcher claimed to solve all differences of environmental issues can be measured properly and deal with better environmental policy framework because there is no substitute for public awareness and all around cooperation.

\section{LIMITATION AND FUTURE STUDY}

The study was limited to the consumers of Hefei (the capital of Anhui, China) and does not cover all States in future studies it would be ideal to look at all the larger States. Secondly, this study is performed on the green environmental advertisements. As such, future studies could focus on specific brands for a better understanding of respondents. In addition, you can choose specific ecological brand so that respondents provided an opportunity to compare eco-labeled products with non-eco labeled and therefore generate more reliable response.

\section{ACKNOWLEDGEMENTS}

The author (Muhammad Usman Saleem) of this paper is thankful to Chinese Government (CSC) scholarship) for Masters research study at University of Science and Technology of China (USTC), Hefei, China.

\section{Reference}

Banerjee, S. B. (1999). Corporate Environmentalism and the Greening of Strategic Marketing: Implications for marketing Theory and Practice. In Charter, M., \& Polonsky, M. J. (Eds.) Greener marketing: A global perspective on greening marketing practice. Sheffield: Greenleaf Publishing Limited. pp. 16-41

Baker, W. E., \& Sinkula, J. M. (2005). Market orientation and the new product paradox. Journal of Product Innovation Management, 22(6), 483-502.

Bearden, I. (2006). Marketing: principles and perspectives. Academic Internet Publishers, Inc. 
BLACKWELL, R., MINIARD, P. E., \& Engel, T. J. (2006): Consumer Behavior. Business and Economics, Mason, OH.

Coddington, Walter. 1993. Environmental Marketing: Positive Strategies for Reaching the Green Consumer. New York: McGraw-Hill Inc.

Carlson, L, Grove, SJ \& Kangun, N 1993, 'A content analysis of environmental advertising claims: a matrix method approach', Journal of Advertising, Vol. 22, No. 3, pp.27-39.

Chan, R. Y. K. (2001). Determinants of Chinese Consumers' Green Purchasing Behaviour. Psychology and Marketing, 18(4), 389-413. http://dx.doi.org/10.1002/mar.1013

D’Souza, C., Taghian, M., Lamb, P., \& Peretiatko, R. (2007). Green decisions: demographics and consumer understanding of environmental labels. International Journal of Consumer Studies, 31(4), 371-376.

Davis, JJ1993, 'Strategies for environmental advertising', Journal of Consumer Marketing, Vol.10, No. 2, pp.19-36.

Dictionary, O. E. (2015). OED online.

Denscombe, M. (2000). Forskningshandboken: för småskaliga forskningsprojekt inom samhällsvetenskapen. Lund: Studentlitteraturen

Fuller, D., 1999. Sustainable marketing: Managerial - ecological issue. Thousand Oaks, CA, Sage.

Foxall, G.R. (1987). Consumer behaviour. In Baker, M.J. (1987). The marketing book. Heinemann Professional Publishing.

Grant, J. (2008). Green marketing. Strategic direction, 24(6), 25-27.

Ghauri, P. N., \& Grønhaug, K. (2005). Research methods in business studies: A practical guide. Pearson Education. Green washing (2009). Green washing report 2009. Available :

http://sinsofgreenwashing.com/findings/greenwashing-report-2009

GlobeScan, A. SustainAbility Survey, 2014. The 2014 SustainAbility Leaders Report.

Hartmann, P., \& Apaolaza Ibáñez, V. (2006). Green value added. Marketing Intelligence \& Planning, 24(7), 673680.

Henion, K. E., \& Kinnear, T. C. (1976). Measuring the effect of ecological information and social class on selected product choice criteria importance ratings. Ecological Marketing, Chicago: American Marketing Association, pp145-156.

Hofstede, G. (2001). Culture's consequences: Comparing values, behaviors, institutions, and organizations across nations (2nd ed.). Thousand Oaks, California: Sage Publications, Inc

Klonoski, R. J. (1991). Foundational considerations in the corporate social responsibility debate. Business Horizons, 34(4), 9-18.

Kangun, N., Carlson, L., \& Grove, S. J. (1991). Environmental advertising claims: a preliminary investigation. Journal of public policy \& marketing, 47-58.

Kotler, P., \& Lee, N. (2008). Corporate social responsibility: Doing the most good for your company and your cause. John Wiley \& Sons.

McCormick, John (2001). „Environmental Policy in the European Union’. The European Series. Palgrave. p. 21.

Nik Abdul Rashid NR. Awareness of eco-label in Malaysia's green marketing initiative. Int J Bus Manage. 2009;4(8):132 - 141

Ottman, J. A. (1994). Green Marketing: Challenges and Opportuni-ties for the New Marketing Age.

Peattie, K. (1999). Trappings versus substance in the greening of marketing planning. Journal of Strategic Marketing, $7(2), 131-148$.

Rushefsky, Mark E. (2002). Public Policy in the United States at the Dawn of the Twenty- first Century (3rd Ed.). New York: M.E. Sharpe, Inc. pp. 253-254. ISBN 978-0- 7656-1663-0. 